\title{
From Lipid Retention to Immune-Mediate Inflammation and Associated Angiogenesis in the Pathogenesis of Atherosclerosis
}

\author{
Ammara Usman ${ }^{1}$, Domenico Ribatti ${ }^{2}$, Umar Sadat ${ }^{3}$ and Jonathan $\mathrm{H}$ Gillard ${ }^{1}$ \\ ${ }^{1}$ University Department of Radiology, Cambridge University Hospitals NHS Foundation Trust, Cambridge, United Kingdom \\ ${ }^{2}$ Department of Basic Medical Sciences, Neurosciences and Sensory Organs, University of Bari Medical School, Bari, Italy; National \\ Cancer Institute "Giovanni Paolo II", Bari, Italy \\ ${ }^{3}$ Cambridge Vascular Unit, Cambridge University Hospitals NHS Foundation Trust, Cambridge, United Kingdom
}

\begin{abstract}
Atherosclerosis is a leading cause of mortality and long-term morbidity worldwide. It is a lipoprotein-driven disease that leads to plaque formation at focal areas in the arterial blood vessels through intimal inflammation, necrosis, fibrosis, and calcification. Adventitial and intimal angiogenesis contributes to the progression of intimal hyperplasia and the development of a necrotic core. The volatile nature of an atheromatous plaque is responsible for approximately $60 \%$ of symptomatic carotid artery diseases and about $75 \%$ of acute coronary events. In this review the pathogenesis of atherosclerosis is discussed from the initial step of lipid retention to advanced stages of immune-mediate inflammation and associated angiogenesis. Mechanisms of plaque rupture are also discussed.
\end{abstract}

J Atheroscler Thromb, 2015; 22: 739-749.

Key words: Atherosclerosis, Plaque, Lipid, Inflammation, Angiogenesis, Stroke, Myocardial infarction

\section{Introduction}

According to the World Health Organization fact sheet, cardiovascular disease (CVD) is the number one cause of death globally. An estimated 17.3 million people died from CVDs in 2008, representing 30\% of all the global deaths ${ }^{1)}$. Of these deaths, an estimated 7.3 million were due to coronary disease $(\mathrm{CAD})$ and 6.2 million due to stroke ${ }^{2}$. The number of people who die from CVD, mainly from heart disease and stroke will increase to reach 23.3 million by $2030^{1,3)}$. CVDs are projected to remain the single leading cause of death, and as a result of the increased disease prevalence and the rising costs of treatments for CVD and the associated risk factors, the economic burden of management of CVD is reaching unsustainable levels, even for developed economies.

The main etiology that leads to CVD is primarily atherosclerosis that causes clinical diseases by lumi-

Address for correspondence: Ammara Usman, Box 218, Level 5 University Department of Radiology, Addenbrooke's Hospital, Hills Road, Cambridge, CB2 0QQ

E-mail:au239@cam.ac.uk

Received: March 20, 2015

Accepted for publication: May 6, 2015 nal narrowing, aggravating thrombi production, and propagation that obstructs the circulation to heart (CAD), brain (ischemic stroke), or lower extremities (peripheral vascular disease). Atherosclerosis is a lipoprotein-driven disease that leads to plaque formation at focal areas in the arterial blood vessels through intimal inflammation, necrosis, fibrosis, and calcification.

\section{Atheromatous Plaques}

A typical atheromatous plaque has a core containing lipids and debris from dead cells, called lipid core (LC) or lipid-rich necrotic core (LRNC). It is covered by a fibrous cap (FC), which contains smooth muscle cells, and collagen fibers that stabilize the plaque. Immune cells including monocytes, T-cells, and mast cells are present in the plaque and mostly in activated state. They produce various cytokines, proteases, pro-thrombotic molecules, and vasoactive substances, which play a role in plaque inflammation and vascular function. Until complications occur, an intact endothelium covers the plaque.

On the basis of the vulnerability status, atheromatous plaques are classified as low-risk /non-vulnerable /stable plaque, characterized by a thick FC and 
low LC, and high risk/vulnerable /unstable plaques.

The term vulnerable plaque was put forward by Muller et al. to describe atherosclerotic plaques prone to rupture ${ }^{4)}$. A consensus paper for the definition of vulnerable plaques in 2003 described their features such as: thin FC with large LC, active inflammation, endothelial denudation with superficial platelet aggregation, a fissured plaque or stenosis $>90 \%{ }^{5)}$. Additional criteria included the presence of intraplaque hemorrhage, superficial calcified nodule, and positive outward remodeling.

The modified American Heart Association classification of atherosclerotic lesions ${ }^{6)}$ defines "thin fibrous cap" as one that is $<65 \mu \mathrm{m}$ thick on the basis that this was the 95th centile cap thickness at the point of rupture in a series of 41 fatally ruptured coronary plaques [mean cap thickness was $23 \mu \mathrm{m}$ at the point of rupture ${ }^{7)}$. For ruptured carotid plaques, the median representative cap thickness of $400 \mu \mathrm{m}$ [interquartile range (IQR): 220 to $600 \mu \mathrm{m}$ ] and the median minimum cap thickness of $200 \mu \mathrm{m}(100$ to $300 \mu \mathrm{m})$ has been observed to discriminate reliably between ruptured and non-ruptured plaques ${ }^{8)}$. There is no cutoff value for the lipid content, which can be used to distinguish vulnerable from non-vulnerable plaques, and the comparison between the two plaque categories is therefore in relative terms.

\section{Pathogenesis}

\section{Role of Lipids}

Lipids play a key role in the development of atherosclerosis. An increase blood concentration of apolipoprotein B containing lipoproteins, of which low density lipoprotein (LDL) is the most prevalent form, can be a sufficient cause of atherosclerosis by accumulating in the arterial intima ${ }^{9)}$ where they may be modified by oxidation and aggregation, such as in familial hypercholesterolemia. However, the disease may develop even at lower levels of LDL in combination with other risk factors that facilitate atherosclerosis. These include smoking, hypertension, diabetes mellitus, male sex, and complex genetic susceptibility to the disease (family history).

ApoB is the main apolipoprotein of LDL and is required for its formation and metabolism. In humans, apoB exists in two isoforms ${ }^{10)}$ : aopB 100 , which is one of the largest proteins in the body, expressed in liver and is thus present on the liver derived lipoproteins very-low-density lipoprotein (VLDL), intermediate density lipoprotein (IDL), and LDL. The other form is apoB 48, which is expressed in the intestine; therefore, it is present on the intestine derived lipoproteins chylomicrons.

Lipoprotein entry and retention within the subendothelial space and hence atherosclerosis depends on sustained plasma levels of apoB lipoproteins. Lipoprotein size, charge, and composition and endothelial permeability may influence lipoprotein entry but less certainty exists in these areas ${ }^{11)}$. Work carried out by Ira Tabas shows that even with low LDL (e.g., in 100 $\mathrm{mg} / \mathrm{dL}$ range) patient still develop CAD indicating that subendothelium that is particularly susceptible to retention or maladaptive responses to retained lipoproteins (e.g., because of genetic or environmental factors) requires lower levels of circulating apoB lipoproteins to initiate the atherogenic process. An important example of this principle is the increased susceptibility of diabetic patients to CAD compared with non-diabetic patients with the same plasma levels of LDL, possibly related to their altered arterial matrix. Therefore, aggressive LDL lowering is particularly successful in lowering CAD risk in diabetics. A recent study showed that treatment of subjects with very low level LDL values (average $50 \mathrm{mg} / \mathrm{dL}$ ) with statins to further lower their LDL was associated with a marked improvement in survival and the prevention of acute coronary syndromes over a 2 -year period ${ }^{12)}$.

In 1995, Dr Kevin Williams and Ira Tabas presented the response-to-retention hypothesis of atherogenesis, which states that retention of atherogenic lipoproteins within the vessel walls is the necessary initiating event of atherogenesis ${ }^{13)}$. The retained lipoproteins subsequently trigger an inflammatory response that leads to the formation of the atherosclerotic lesions ${ }^{14)}$

The hypothesis is based on pioneering work in 1970 s and 1980s showing that apoB 100 containing lipoproteins from plasma can interact with the extracellular matrix (ECM) in the arterial wall ${ }^{15-17)}$. Apolipoprotein $\mathrm{B}$ containing lipoproteins binds to proteoglycans in the vessel wall because lipoproteins up to 70 $\mathrm{nm}$ in diameter can cross an intact endothelium through transcytosis. LDL and IDL are easily taken up by the arterial wall ${ }^{18,19)}$. The main determinants seem to be the lipoprotein characteristics and the capacity of the vessel wall to bind lipoproteins.

The retained lipoproteins adhere to the vessel wall mostly through electrostatic binding to proteoglycans (such as heparin sulfate, chondroitin sulfate, dermatan sulfate, and keratin sulfate) in the ECM ${ }^{20}$. There are various sites on apoB 100 for binding. Site $\mathrm{B}$ is the major site for proteoglycan binding ${ }^{10)}$. Site A is exposed when LDL is modified by secretory phospholipase A2 (sPLA2), which hydrolyses surface phospholipids on LDL resulting in a smaller and more 


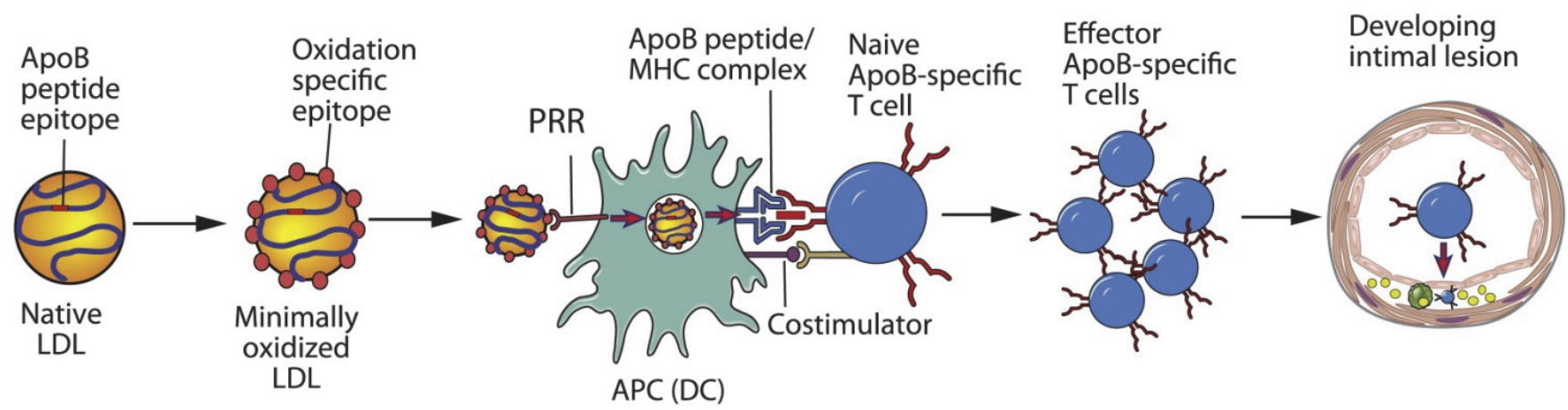

Fig. 1. A potential role for low-density lipoprotein as an antigen that promotes atherosclerosis. Native LDL can undergo slight oxidative modification that permits its uptake by pattern recognition receptors (PRRs) on antigen precursor cells (APCs) (which may include DCs) but does not sufficiently alter amino acid side chains in ApoB to interfere with immunogenicity. The ApoB-derived proteins, presented in the context of self-major histocompatibility complex (MHC), with appropriate co-stimulation, stimulate proliferation of the antigen-specific T-cell clone and aggravation of atherogenesis (reproduced with permission, Libby $\mathrm{P}$ et al., Immune effector mechanisms implicated in atherosclerosis: from mice to humans. Immunity, 2013; 38: 1092-1104).

dense LDL particle, sPLA2-modified lipoproteins display increased affinity for proteoglycans ${ }^{21)}$ and an elevated plasma level of sPLA2 is a strong risk factor for cardiovascular disease ${ }^{22)}$.

In addition to apoB, several other apolipoproteins (including apoE and serum amyloid A) also have proteoglycan-binding domain. The intestinal-derived chylomicrons (which contain apoB48 and apoE) may play an important role despite the big size to penetrate the intact endothelium, their remnants are found in the arterial wall ${ }^{23,24}$. Because of their larger size each trapped particle contributes a large amount of lipids, and therefore, only a modest accumulation of chylomicron remnants may significantly contribute to vascular lipid deposition.

HDL, which contains apoE and serum amyloid A, localizes in the arterial wall ${ }^{25)}$, and oxidized HDL has been detected within the human atherosclerotic lesions ${ }^{26)}$. Cell culture studies show that the macrophage scavenger receptor CD36 mediates the uptake of oxidized HDL but not native $\mathrm{HDL}^{27}$. Hence, although high plasma levels of HDL are strongly correlated with protection against cardiovascular disease, HDL may be pro-atherogenic once it is trapped in the arterial wall.

Lipoproteins retained in the intima are exposed to oxidizing agents and enzymes that lead to oxidized and aggregated LDL particles, which are then recognized and engulfed by the macrophages (Fig. 1). The LDL-proteoglycan binding also stimulates macrophages to engulf LDL mostly because of the physical alteration of LDL upon binding to proteoglycans, including a change in both the apoB100 configuration and in the lipid organization ${ }^{28-30)}$. These changes in structure make proteoglycan-bound LDL even more susceptible to oxidation and aggregation ${ }^{31,32)}$.

Lipoprotein retention seems to be a self-accelerating process, in which retained LDL evokes cellular responses that lead to additional LDL entrapment. First, oxidized LDL and cytokines released from inflammatory cells stimulate smooth muscle cells (SMCs) to proliferate and secrete proteoglycans with elongated proteoglycan chains that have an increased affinity for LDL ${ }^{33},{ }^{34)}$. Second, the infiltrated macrophages secrete bridging molecules mostly lipoprotein lipase (LPL), which further enhances the lipoprotein retention ${ }^{35)}$. LPL is a positively charged enzyme, which is normally attached to a negatively charged proteoglycans in the lumen of capillaries where it captures circulating lipoproteins. Because it has binding sites for both proteoglycans and lipoproteins, macrophage derived LPL increases the vessel wall affinity for lipoproteins by serving as a bridge between the proteoglycans and lipoproteins ${ }^{36,37)}$.

Aggregation of LDL particles increases their binding to proteoglycans and further boosts the inflammatory response ${ }^{38)}$. Hence, lipoprotein retention is the initiator of a viscous circle that leads to increased lipoprotein retention, increased inflammation, and eventually the formation of atherosclerotic lesion.

\section{Inflammation and Immune System Interaction}

The intramural retention of cholesterol rich apolipoprotein B containing lipoproteins in the susceptible areas of arterial vasculature leads to maladaptive 


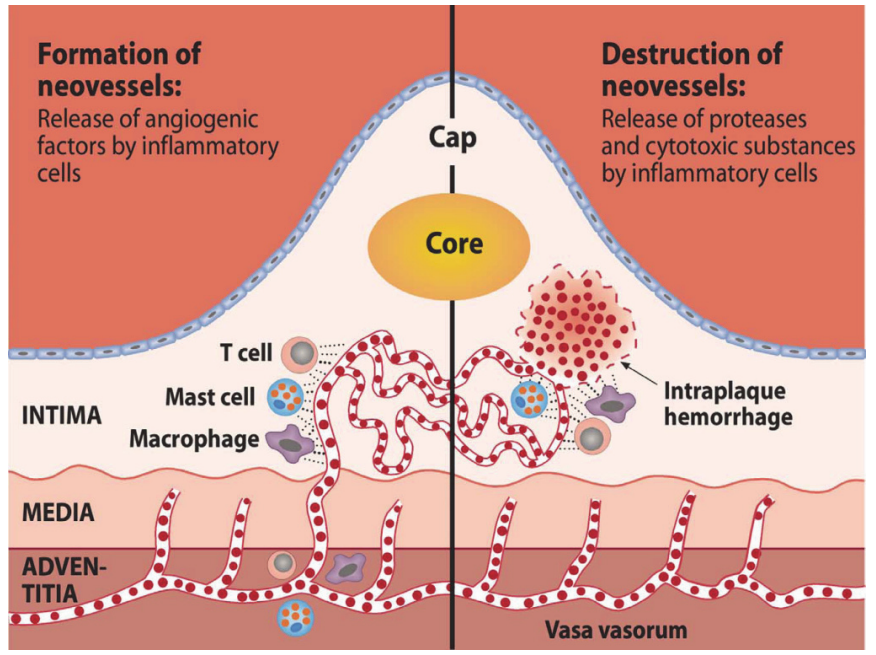

$1 \mathrm{~A}$

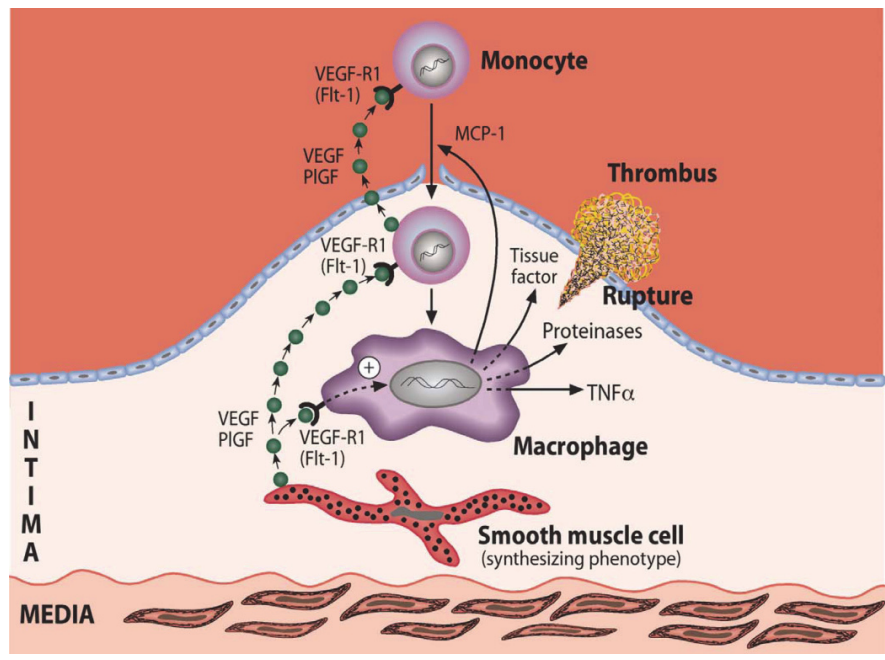

1B

Fig. 2. (A): Schematic presentation of the two roles of an infiltrate of pro-inflammatory cells in an advanced atherosclerotic lesion: left angiogenic and right angiolytic effects. (B): Pro-inflammatory effects of VEGF/PIGF on an advanced atherosclerotic plaque (reproduced with permission, Ribatti D et al., Inflammatory angiogenesis in atherogenesis--a double-edged sword. Ann Med, 2008; 40: 606-621).

inflammatory response. These sequestered lipoproteins are susceptible to various modifications such as oxidation, enzymatic and non-enzymatic cleavage, and aggregation, which make these particles more pro inflammatory and induce the activation of overlying endothelium. The key early inflammatory response to retained apoB-LPs, which may be enhanced by oxidative modification of the LPs, is the activation of overlying endothelial cells in a manner that leads to the recruitment of blood-borne monocytes into subendothelial space ${ }^{39,40)}$.

The activated endothelial cells secrete chemoattractants or chemokines that interacts with the chemokine receptors on monocytes and promotes their directional migration. Monocytes primarily originate from bone marrow-derived progenitor cells and this early stage of monocyte development may be regulated by cellular cholesterol content in a manner that can affect atherogenesis ${ }^{41)}$.

Monocytes adhere and roll on the endothelial cells overlying retained apoB-LPs and adhere firmly to lesional endothelial cells through the interaction of integrins with the endothelial cells ligand ${ }^{40}$. Platelet aggregation on endothelium overlying atherosclerosis also activates adhesion molecule expression through the deposition of platelet-derived chemokines on activated endothelium ${ }^{42)}$. These finally lead to the entry of monocytes into sub-endothelial space ${ }^{43}$. Within the intima the monocytes secrete lipoprotein binding proteoglycans resulting in the increased accumulation of modified LDL, which sustains inflammation ${ }^{13,44)}$. The endothelial cell itself also becomes activated and expresses chemokines and proteases, thereby perpetuating the inflammatory response. Once in the intima, monocytes under the influence of monocyte colony stimulating factor (M-CSF) either changes to macrophages or dendritic cells ${ }^{45)}$.

When the macrophages ingest and process apoBLPs and the uptake exceeds efflux or the efflux is disturbed, lipids accumulate resulting in the formation of "foam cells." Macrophage foam cells promote further growth and destabilization of the plaque: secretion of cytokines and chemokines, generation of reactive oxygen species (ROS), presentation of immune activation markers to lymphocytes or macrophage scavenger receptor, production of matrix-degrading proteases (i.e., matrix metalloproteinases (MMPs), and release of inflammatory debris into the plaque core following necrosis or apoptosis. The process is accelerated by amplified lipoprotein retention in established lesions.

SMCs migrate into the intima and promote formation of a collagenous FC (which is initially thick), probably representing a scar-like response to wall off the lesion. Macrophages congregate in a central core in the typical atherosclerotic plaque and can die, some by apoptosis, hence producing the so-called 'necrotic core' of the atherosclerotic lesion. As the lesion progresses and the inflammatory activity increases, it results in fibrous cap thinning, plaque erosion, or rupture, ultimately leading to acute thrombotic vascular 
events such as myocardial infarction and stroke.

Both humoral and cell mediated immunity are involved in the development and progression of the atherosclerotic plaque ${ }^{46)}$.

$\mathrm{T}$ lymphocytes are seen in the atherosclerotic plaques at nearly all stages of development. Most $\mathrm{T}$ lymphocytes within atherosclerotic lesions belong to the CD4 + Th1 T cell subtype. Oxidized LDL, heat shock proteins, and microbial proteins are possible mediators of T-cell activation within the atherosclerotic plaque ${ }^{47)}$. Activated CD4 + T lymphocytes contribute to plaque vulnerability by producing proinflammatory cytokines, including interferon gamma $($ IFN $-\gamma)$, and tumor necrosis factor alpha $(\text { TNF- } \alpha)^{48)}$.

B Lymphocytes have been detected by immunohistochemistry in advanced human atherosclerotic lesions, but their precise role is not known ${ }^{49)}$. It has been suggested that B cell mediated adaptive immunity may play an atheroprotective role, in contrast to the proatherogenic role of monocytes and T-lymphocytes $^{50)}$.

Mast cells have the potential to play a critical role in destabilization of the atherosclerotic lesion. While allergen binding to $\mathrm{IgE}$ is the classic mediator of mast cell degranulation, other stimuli more likely to occur in the context of the vulnerable plaque can also provoke this phenomenon. These include soluble factors secreted by activated T-cells or macrophages ${ }^{51)}$ and collagen derived peptides ${ }^{52}$. During degranulation heparin, inflammatory mediators such as histamine and neutral proteases such as tryptase and chymase are released into the surrounding medium. Activated mast cells are were identified in the regions of plaque rupture, and it is thought that their neutral proteases may serve to trigger the activation of macrophage-released $\mathrm{MMPs}^{53)}$.

\section{Angiogenesis and Neovascularisation}

Adventitial and intimal angiogenesis contributes to the progression of intimal hyperplasia and the development of a necrotic core. Angiogenesis in the atherosclerotic plaque has been investigated as a possible factor, which contributes to the risk of rupture ${ }^{54)}$ (Fig. 2A). It can be considered as a compensatory response to hypoxia present in the deep intimal and medial areas produced by the proliferation of the intimal SMCs and resulting in local thickening of the intima, as the plaque grows ${ }^{55-57)}$.

A possible role of hypoxia inducible factor (HIF) in atherosclerosis is supported by the presence of intraplaque angiogenesis and the implication of several known HIF-responsive genes in atherosclerosis, associated with vascular endothelial growth factor (VEGF) ${ }^{58)}$,
Table 1. Pro-angiogenic and anti-angiogenic factors present in atherosclerotic plaques

Pro-angiogenic
Vascular endothelial growth factor (VEGF)
Placental growth factor (PIGF)
Fibroblast growth factor-2 (FGF-2)
Platelet derived growth factor (PDGF)
Transforming growth factor beta (TGF- $\beta$ )
Interleukin 8 (IL-8)
Monocyte chemoattractant protein-1 (MCP-1)
Tumor necrosis factor alpha (TNF $\alpha$ )
Endothelin-1 (ET-1)
Thrombin
Matrix metalloproteinases (MMP)
Platelet activating factor (PAF)
Nitric oxide (NO)
Heme oxygenase-1 (HO-1)
Cyclooxygenase-2 (COX-2)
Oxidized phospholipids (oxPL)
Anti-angiogenic
Thrombospondin-1 (TSP-1)
Angiostatin
Platelet factor 4
Perlecan
Collagen IV
Endlagen XVIII
Endostatin

endothelin-1 ${ }^{59)}$ and MMP-2 ${ }^{60)}$. More recently, Sluimer et al ${ }^{61)}$ provided a direct evidence of a correlation between hypoxia, the presence of macrophages, and the expression of HIF and VEGF in advanced human atherosclerosis. Moreover, the HIF pathway was associated with lesion progression and angiogenesis, suggesting its involvement in the response to hypoxia and the regulation of intraplaque angiogenesis.

The hypoxemia theory of atherosclerosis postulates that an imbalance between the demand and supply of oxygen in the arterial wall is important for the development of atherosclerotic lesions ${ }^{62)}$.

On the other hand, atherosclerotic lesions responsible for vascular occlusion are themselves associated with angiogenesis within the vessel wall. An imbalance between the inducers and inhibitors, with a predominance of the former, is essential for the induction of neovascularization in the atherosclerotic arterial wall, and the angiogenic switch may be the consequence of a down-regulation in the expression of two or even more angiogenesis inhibitors ${ }^{63)}$.

Several angiogenic and antiangiogenic factors 


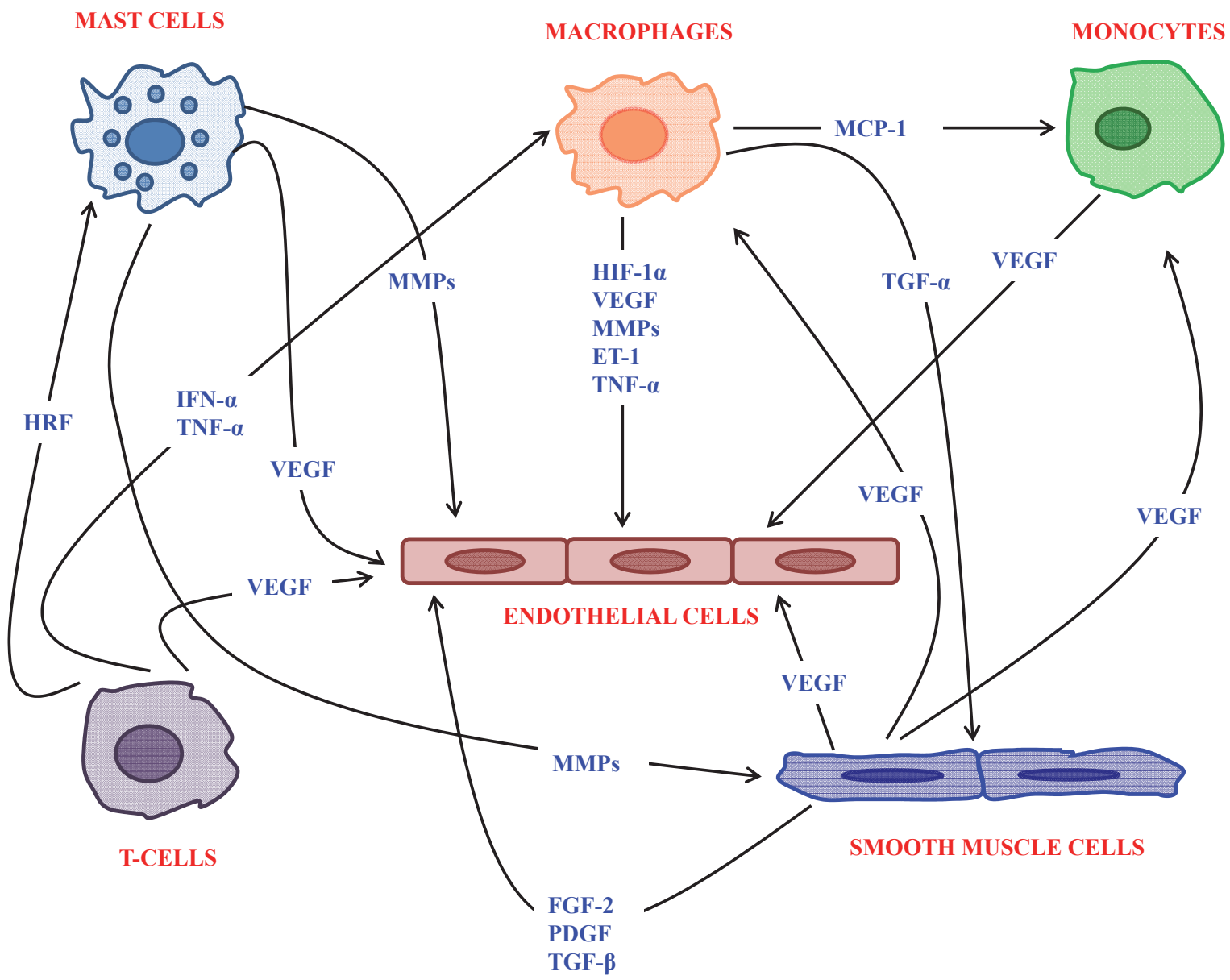

Fig. 3. Interplay between angiogenic molecules secreted by mast cells, monocytes, macrophages, T-cells, and smooth muscle cells in the atherosclerotic plaque

have been identified in atherosclerotic plaques (Table 1). VEGF/VEGF receptors (VEGFRs) signaling plays the most important role ${ }^{64)}$ (Fig. 2B). The secreted VEGF reaches the adjacent macrophage and bind to the VEGFR-1. Binding of VEGF to its receptor stimulates the macrophage to synthesize and secrete monocyte chemotactic protein-1 (MCP-1), which attracts circulating monocytes to enter the plaque. In the subendothelial space, VEGF stimulates the monocytes via VEGFR-1 to synthesize and secrete VEGF, which contributes to recruitment of monocytes into the plaque. VEGF also induces the macrophage to synthesize and secrete the proinflammatory cytokine tumor necrosis factor-alpha (TNF- $\alpha$ ). As a result of the VEGF-dependent secretion of matrix-degrading proteinases, the plaque ruptures, and a mural thrombus forms when blood comes in contact with the subendothelial tissue ${ }^{58,65)}$.

The administration of VEGF to apoE-deficient mice promotes angiogenesis and macrophage infiltra- tion in atherosclerotic plaques ${ }^{58)}$. On the other hand, the administration of anti-VEGFR-1 antibody to apoE-deficient mice reduces plaque development and increases plaque stability via the impaired infiltration of monocytes into the intimal area ${ }^{66}$. Fibroblast growth factor-2 (FGF-2) has been demonstrated in areas of neovascularization, and smooth muscle cells, foam cells, and the plaque microvasculature display co-expression of FGF-receptor-1 (FGFR-1) and FGFR-2 ${ }^{67)}$

Inflammatory cells such as macrophages, T- cells, and mast cells are present in the areas of neovascularization (Fig. 3). Mast cells accumulate in the shoulder regions of human coronary atheroma and the predilection site of atheromatous rupture ${ }^{68)}$. T lymphocytes are present in the areas of neoangiogenesis, particularly deep within the intima and below the necrotic core and shoulder region ${ }^{69)}$. Inflammatory cells secrete several angiogenic cytokines, such as VEGF, FGF-2, transforming growth factor beta (TGF- $\beta)$, TNF- $\alpha$, 
and various destabilizing proteases.

The newly formed vascular supply contributes to the perpetuation of chronic inflammation by promoting the migration of inflammatory cells to the site of inflammation by the upregulation of adhesion molecules, thus amplifying the inflammatory response $\mathrm{e}^{70)}$. In atherosclerotic plaques, pro-inflammatory cells not only induce the growth of new microvessels in the deep areas of advanced plaques but also may facilitate rupture of fragile neovessels and consequent intraplaque hemorrhage. The angiogenic potential of inflammatory cells initially serves a healing function but later, as the disease advances, a detrimental function.

Extracellular proteolysis is an absolute requirement for angiogenesis. Specifically, a role for MMPs, the urokinase-type plasminogen activator (PA) receptor, and PA inhibitor 1 (PAI-1) has been clearly defined in a number of model systems ${ }^{71}$. By the selective and targeted degradation of the pericellular and ECM, MMPs promote sprouting of vasa vasorum in regions of hypoxia and also promote the release of VEGF and FGF-2. Similarly, plasmin facilitates the release of VEGF from the extracellular matrix into its bioactive form. Angiogenesis in the plaque is perpetuated by thrombotic events occurring in some of the new microvessels, which again are triggered by local microhemorrhages originating in the microvessels.

In the atherosclerotic vessel, angiogenic agents stimulate both prothrombotic PA and PAI-1 gene expression in vascular endothelial cells and smooth muscle cells ${ }^{72)}$. Furthermore, overexpression of the PA system may be responsible for increasing the activity of some MMPs ${ }^{73)}$. The neovascularized regions of the plaques express active forms of the various MMPs, and the microvessels themselves are positive for $\mathrm{MMPs}^{74)}$. Thus, it is likely that some of the plaque-destabilizing effects of MMP activity in the vulnerable areas of plaques are derived from the suggested ability of MMPs to trigger microvessel leakage with ensuing intraplaque hemorrhage ${ }^{75)}$. Macrophages secrete MMP, hydrolytic enzymes including myeloperoxidase and tissue factor, which may increase the risk of arterial thrombosis at the time of plaque rupture ${ }^{76-78)}$.

\section{Why Plaques Rupture?}

The volatile nature of an atheromatous plaque is responsible for approximately $60 \%$ of symptomatic carotid artery diseases and about $75 \%$ of acute coronary events. Plaque rupture is more likely to occur in the region where the cap is the thinnest and infiltrated by foam cells. In eccentric plaques, the weakest point is mostly the cap margin or shoulder region. Examina- tion of intact and disrupted plaques and in vitro mechanical testing of isolated fibrous caps indicate that vulnerability to rupture depends on ${ }^{79)}$ : size and consistency of atheromatous core, thickness and collagen content of the fibrous cap covering the core, inflammation within the cap and mechanical stresses.

The size and consistency of the atheromatous core vary greatly from plaque to plaque and are critical for the stability of individual lesion. Although the average stenotic coronary plaque contains more hard fibrous tissue then soft atheromatous gruel, its presence could be the culprit in causing the acute coronary syndrome ${ }^{80)}$.

Absence of necrotic core results in the absence of the overlying fibrous cap to rupture. Larger necrotic core also confers greater risk than a small one ${ }^{81,82}$. The importance of the necrotic core size for plaque stability is comprehensible because the expansion of the core may erode the FC from below and because the total lack of supporting collagen in the lipid-rich core confers greater tensile stress to the overlying FC. A large necrotic core may also increase the thrombogenecity of the plaque material and hence the risk of clinical event in case of plaque ruptures ${ }^{83)}$.

The thickness and collagen content of FC are important for the stability of a plaque ${ }^{84)}$. FCs vary widely in thickness, cellularity, matrix strength, and stiffness, but they are often the thinnest (and macrophages infiltrated) at their shoulder regions where disruption most frequently occurs ${ }^{85)}$. Collagen is important for the tensile the strength of tissues, and disrupted aortic cap contain fewer SMCs (the collagensynthesizing cell in plaques) and less collagen than in intact caps ${ }^{86)}$. Microscopic assessment of the autopsy study of sudden cardiac death showed that the average thickness of ruptured caps was found to be only 23 $\mu \mathrm{m}$ and $95 \%$ of ruptured caps were below $65 \mu \mathrm{m}^{7}$.

Disrupted FCs usually are heavily infiltrated by macrophage foam cells. These rupture-related macrophages are activated, indicating ongoing inflammation at the site of plaque disruption ${ }^{79)}$.

Disruption of FC, rich in macrophages and T-lymphocytes, in addition to the necrotic core coming in contact with circulating blood, are events that lead to the development of thrombi in fatal plaques ${ }^{6,87)}$. Over the last decade, much interest has been focused on the role of MMPs as the main cause of FC disruption in plaque rupture. Collagen type I provides most of the tensile strength of the FC and certain pro inflammatory cytokines, such as interferon-gamma (IFN- $y)$, inhibit collagen synthesis by $\mathrm{SMCs}^{88}$. The initial proteolytic nick in the collagen chain is provided by MMP- 1, -8, and -13, whereas MMP-2 and 
-9 supports the collagen break down ${ }^{87-92)}$. However, the artery also possesses endogenous tissue inhibitors of metalloproteinases (TIMPs) ${ }^{93)}$. It has been shown that atheromatous rather than fibrous plaques preferentially exhibit type I collagen cleavage, occurring at sites that are rich in macrophages expressing both MMP-1 and -13 ${ }^{92)}$. Other proteinases capable of degrading ECM are cathepsin $S$ and $\mathrm{K}^{94)}$. However, cathepsins possess potent elastolytic activity and have been implicated more with matrix remodeling and migration and the proliferation of cells ${ }^{90)}$. While elastolysis may be more important in aneurysm formation, collagenolysis may be a major determinant of plaque rupture ${ }^{95)}$. Although we believe that both collagenolysis and elastolysis are important in the atherosclerotic process, the actual rupture event may reflect local factors related to blood flow dynamics ${ }^{96)}$.

\section{Concluding Remarks}

Despite the complexity of advanced atherosclerosis a clear root cause exists, that is lipoprotein retention and oxidation lead to the initiation of an inflammatory cascade and immune interactions that promote lesion development to the point of acute thrombotic complications and clinical events. Extensive understanding of the pathogenesis of this leading killer could lead to its eradication. It has the potential to identify targets that can be used for making early diagnosis using non-invasive imaging techniques and utilizing appropriate therapeutic interventions on the basis of the pathological stage of the disease. Apart from the LDL-lowering therapies, extensive research is required on the role of anti-inflammatory and/or immune-modulating drugs to target the inflammatory component of atherogenesis. Perhaps by combining these two treatment modalities the survival rate may improve.

\section{Conflicts of Interest}

None.

\section{References}

1) WHO. Global staus report on non communicable diseases 2010. WHO Press, World Health Organization, 20 Avenue Appia, 1211 Geneva 27, Switzerland 2011

2) WHO. Global atlas on cardiovascular disease prevention and control 2011. Fact sheet $\mathrm{N}^{\circ} 317$

3) Mathers CD, Loncar D: Projections of global mortality and burden of disease from 2002 to 2030. PLoS Med, 2006; 3: e442

4) Muller JE, Abela GS, Nesto RW, Tofler GH: Triggers, acute risk factors and vulnerable plaques: the lexicon of a new frontier. J Am Coll Cardiol, 1994; 23: 809-813

5) Naghavi M, Libby P, Falk E, Casscells SW, Litovsky S, Rumberger J, Badimon JJ, Stefanadis C, Moreno P, Pasterkamp G, Fayad Z, Stone PH, Waxman S, Raggi P, Madjid M, Zarrabi A, Burke A, Yuan C, Fitzgerald PJ, Siscovick DS, de Korte CL, Aikawa M, Juhani Airaksinen KE, Assmann G, Becker CR, Chesebro JH, Farb A, Galis ZS, Jackson C, Jang IK, Koenig W, Lodder RA, March K, Demirovic J, Navab M, Priori SG, Rekhter MD, Bahr R, Grundy SM, Mehran R, Colombo A, Boerwinkle E, Ballantyne C, Insull W, Jr., Schwartz RS, Vogel R, Serruys PW, Hansson GK, Faxon DP, Kaul S, Drexler H, Greenland P, Muller JE, Virmani R, Ridker PM, Zipes DP, Shah PK, Willerson JT: From vulnerable plaque to vulnerable patient: a call for new definitions and risk assessment strategies: Part I. Circulation, 2003; 108: 1664-1672

6) Virmani R, Kolodgie FD, Burke AP, Farb A, Schwartz SM: Lessons from sudden coronary death: a comprehensive morphological classification scheme for atherosclerotic lesions. Arterioscler Thromb Vasc Biol, 2000; 20: 1262-1275

7) Burke AP, Farb A, Malcom GT, Liang YH, Smialek J, Virmani R: Coronary risk factors and plaque morphology in men with coronary disease who died suddenly. N Engl J Med, 1997; 336: 1276-1282

8) Redgrave JN, Gallagher P, Lovett JK, Rothwell PM: Critical cap thickness and rupture in symptomatic carotid plaques: the oxford plaque study. Stroke, 2008; 39: 17221729

9) Nakashima Y, Wight TN, Sueishi K: Early atherosclerosis in humans: role of diffuse intimal thickening and extracellular matrix proteoglycans. Cardiovasc Res, 2008; 79: 14-23

10) Fogelstrand P, Boren J: Retention of atherogenic lipoproteins in the artery wall and its role in atherogenesis. Nutr Metab Cardiovasc Dis, 2012; 22: 1-7

11) Tabas I, Williams KJ, Boren J: Subendothelial lipoprotein retention as the initiating process in atherosclerosis: update and therapeutic implications. Circulation, 2007; 116: 18321844

12) Leeper NJ, Ardehali R, deGoma EM, Heidenreich PA: Statin use in patients with extremely low low-density lipoprotein levels is associated with improved survival. Circulation, 2007; 116: 613-618

13) Williams KJ, Tabas I: The response-to-retention hypothesis of early atherogenesis. Arterioscler Thromb Vasc Biol, 1995; 15: 551-561

14) Nakashima Y, Fujii H, Sumiyoshi S, Wight TN, Sueishi K: Early human atherosclerosis: accumulation of lipid and proteoglycans in intimal thickenings followed by macrophage infiltration. Arterioscler Thromb Vasc Biol, 2007; 27: 1159-1165

15) Camejo G, Lopez A, Vegas H, Paoli H: The participation of aortic proteins in the formation of complexes between low density lipoproteins and intima-media extracts. Atherosclerosis, 1975; 21: 77-91

16) Camejo G, Lalaguna F, Lopez F, Starosta R: Characterization and properties of a lipoprotein-complexing proteoglycan from human aorta. Atherosclerosis, 1980; 35: 307320 
17) Vijayagopal P, Srinivasan SR, Radhakrishnamurthy B, Berenson GS: Interaction of serum lipoproteins and a proteoglycan from bovine aorta. J Biol Chem, 1981; 256: 8234-8241

18) Nordestgaard BG, Wootton R, Lewis B: Selective retention of VLDL, IDL, and LDL in the arterial intima of genetically hyperlipidemic rabbits in vivo. Molecular size as a determinant of fractional loss from the intima-inner media. Arterioscler Thromb Vasc Biol, 1995; 15: 534-542

19) Simionescu N, Simionescu M: Cellular interactions of lipoproteins with the vascular endothelium: endocytosis and transcytosis. Targeted Diagn Ther, 1991; 5: 45-95

20) Camejo G: The interaction of lipids and lipoproteins with the intercellular matrix of arterial tissue: its possible role in atherogenesis. Adv Lipid Res, 1982; 19: 1-53

21) Sartipy P, Camejo G, Svensson L, Hurt-Camejo E: Phospholipase $A(2)$ modification of low density lipoproteins forms small high density particles with increased affinity for proteoglycans and glycosaminoglycans. J Biol Chem, 1999; 274: 25913-25920

22) Kugiyama K, Ota Y, Takazoe K, Moriyama Y, Kawano H, Miyao Y, Sakamoto T, Soejima H, Ogawa H, Doi H, Sugiyama S, Yasue H: Circulating levels of secretory type II phospholipase $\mathrm{A}(2)$ predict coronary events in patients with coronary artery disease. Circulation, 1999; 100: 12801284

23) Chung BH, Tallis G, Yalamoori V, Anantharamaiah GM, Segrest JP: Liposome-like particles isolated from human atherosclerotic plaques are structurally and compositionally similar to surface remnants of triglyceride-rich lipoproteins. Arterioscler Thromb, 1994; 14: 622-635

24) Twickler T, Dallinga-Thie GM, Chapman MJ, Cohn JS: Remnant lipoproteins and atherosclerosis. Curr Atheroscler Rep, 2005; 7: 140-147

25) O’Brien KD, Olin KL, Alpers CE, Chiu W, Ferguson M, Hudkins K, Wight TN, Chait A: Comparison of apolipoprotein and proteoglycan deposits in human coronary atherosclerotic plaques: colocalization of biglycan with apolipoproteins. Circulation, 1998; 98: 519-527

26) Nakajima T, Origuchi N, Matsunaga T, Kawai S, Hokari S, Nakamura H, Inoue I, Katayama S, Nagata A, Komoda $\mathrm{T}$ : Localization of oxidized HDL in atheromatous plaques and oxidized HDL binding sites on human aortic endothelial cells. Ann Clin Biochem, 2000; 37 (Pt 2): 179-186

27) Thorne RF, Mhaidat NM, Ralston KJ, Burns GF: CD36 is a receptor for oxidized high density lipoprotein: implications for the development of atherosclerosis. FEBS Lett, 2007; 581: 1227-1232

28) Camejo G, Hurt E, Wiklund O, Rosengren B, Lopez F, Bondjers G: Modifications of low-density lipoprotein induced by arterial proteoglycans and chondroitin-6-sulfate. Biochim Biophys Acta, 1991; 1096: 253-261

29) Mateu L, Avila EM, Camejo G, Leon V, Liscano N: The structural stability of low-density lipoprotein. A kinetic X-ray scattering study of its interaction with arterial proteoglycans. Biochim Biophys Acta, 1984; 795: 525-534

30) Hurt E, Bondjers G, Camejo G: Interaction of LDL with human arterial proteoglycans stimulates its uptake by human monocyte-derived macrophages. J Lipid Res, 1990; 31: 443-454
31) Hurt-Camejo E, Camejo G, Rosengren B, Lopez F, Ahlstrom C, Fager G, Bondjers G: Effect of arterial proteoglycans and glycosaminoglycans on low density lipoprotein oxidation and its uptake by human macrophages and arterial smooth muscle cells. Arterioscler Thromb, 1992; 12: $569-583$

32) Upritchard JE, Sutherland WH: Oxidation of heparintreated low density lipoprotein by peroxidases. Atherosclerosis, 1999; 146: 211-219

33) Camejo G, Fager G, Rosengren B, Hurt-Camejo E, Bondjers G: Binding of low density lipoproteins by proteoglycans synthesized by proliferating and quiescent human arterial smooth muscle cells. J Biol Chem, 1993; 268: 14131-14137

34) Chang MY, Potter-Perigo S, Tsoi C, Chait A, Wight TN: Oxidized low density lipoproteins regulate synthesis of monkey aortic smooth muscle cell proteoglycans that have enhanced native low density lipoprotein binding properties. J Biol Chem, 2000; 275: 4766-4773

35) Gustafsson M, Levin M, Skalen K, Perman J, Friden V, Jirholt P, Olofsson SO, Fazio S, Linton MF, Semenkovich CF, Olivecrona G, Boren J: Retention of low-density lipoprotein in atherosclerotic lesions of the mouse: evidence for a role of lipoprotein lipase. Circ Res, 2007; 101: 777783

36) Babaev VR, Fazio S, Gleaves LA, Carter KJ, Semenkovich CF, Linton MF: Macrophage lipoprotein lipase promotes foam cell formation and atherosclerosis in vivo. J Clin Invest, 1999; 103: 1697-1705

37) Wilson K, Fry GL, Chappell DA, Sigmund CD, Medh JD: Macrophage-specific expression of human lipoprotein lipase accelerates atherosclerosis in transgenic apolipoprotein e knockout mice but not in C57BL/6 mice. Arterioscler Thromb Vasc Biol, 2001; 21: 1809-1815

38) Oorni K, Hakala JK, Annila A, Ala-Korpela M, Kovanen PT: Sphingomyelinase induces aggregation and fusion, but phospholipase A2 only aggregation, of low density lipoprotein (LDL) particles. Two distinct mechanisms leading to increased binding strength of LDL to human aortic proteoglycans. J Biol Chem, 1998; 273: 29127-29134

39) Glass CK, Witztum JL: Atherosclerosis. the road ahead. Cell, 2001; 104: 503-516

40) Mestas J, Ley K: Monocyte-endothelial cell interactions in the development of atherosclerosis. Trends Cardiovasc Med, 2008; 18: 228-232

41) Yvan-Charvet L, Pagler T, Gautier EL, Avagyan S, Siry RL, Han S, Welch CL, Wang N, Randolph GJ, Snoeck HW, Tall AR: ATP-binding cassette transporters and HDL suppress hematopoietic stem cell proliferation. Science, 2010; 328: 1689-1693

42) Koenen RR, von Hundelshausen P, Nesmelova IV, Zernecke A, Liehn EA, Sarabi A, Kramp BK, Piccinini AM, Paludan SR, Kowalska MA, Kungl AJ, Hackeng TM, Mayo KH, Weber C: Disrupting functional interactions between platelet chemokines inhibits atherosclerosis in hyperlipidemic mice. Nat Med, 2009; 15: 97-103

43) Kamei M, Carman CV: New observations on the trafficking and diapedesis of monocytes. Curr Opin Hematol, 2010; 17: 43-52

44) Tabas I: Macrophage death and defective inflammation 
resolution in atherosclerosis. Nat Rev Immunol, 2010; 10: 36-46

45) Johnson JL, Newby AC: Macrophage heterogeneity in atherosclerotic plaques. Curr Opin Lipidol, 2009; 20: 370378

46) Hansson GK: Cell-mediated immunity in atherosclerosis. Curr Opin Lipidol, 1997; 8: 301-311

47) Xu Q, Willeit J, Marosi M, Kleindienst R, Oberhollenzer F, Kiechl S, Stulnig T, Luef G, Wick G: Association of serum antibodies to heat-shock protein 65 with carotid atherosclerosis. Lancet, 1993; 341: 255-259

48) Hansson GK: Immune mechanisms in atherosclerosis. Arterioscler Thromb Vasc Biol, 2001; 21: 1876-1890

49) Zhou X, Hansson GK: Detection of B cells and proinflammatory cytokines in atherosclerotic plaques of hypercholesterolaemic apolipoprotein E knockout mice. Scand J Immunol, 1999; 50: 25-30

50) Hansson GK: The B cell: a good guy in vascular disease? Arterioscler Thromb Vasc Biol, 2002; 22: 523-524

51) Liu MC, Proud D, Lichtenstein LM, MacGlashan DW Jr, Schleimer RP, Adkinson NF Jr, Kagey-Sobotka A, Schulman ES, Plaut M: Human lung macrophage-derived histamine-releasing activity is due to IgE-dependent factors. J Immunol, 1986; 136: 2588-2595

52) Wize J, Wojtecka-Lukasik E, Maslinski S: Collagen-derived peptides release mast cell histamine. Agents Actions, 1986; 18: 262-265

53) Johnson JL, Jackson CL, Angelini GD, George SJ: Activation of matrix-degrading metalloproteinases by mast cell proteases in atherosclerotic plaques. Arterioscler Thromb Vasc Biol, 1998; 18: 1707-1715

54) Nakano T, Ninomiya T, Sumiyoshi S, Onimaru M, Fujii H, Itabe H, Nakashima Y, Sueishi K, Tsuruya K, Oda Y, Kitazono T, Kiyohara Y: Chronic kidney disease is associated with neovascularization and intraplaque hemorrhage in coronary atherosclerosis in elders: results from the Hisayama Study. Kidney Int, 2013; 84: 373-380

55) Williams JK, Armstrong ML, Heistad DD: Vasa vasorum in atherosclerotic coronary arteries: responses to vasoactive stimuli and regression of atherosclerosis. Circ Res, 1988; 62: 515-523

56) Kwon HM, Sangiorgi G, Ritman EL, McKenna C, Holmes DR Jr, Schwartz RS, Lerman A: Enhanced coronary vasa vasorum neovascularization in experimental hypercholesterolemia. J Clin Invest, 1998; 101: 1551-1556

57) Galili O, Sattler KJ, Herrmann J, Woodrum J, Olson M, Lerman LO, Lerman A: Experimental hypercholesterolemia differentially affects adventitial vasa vasorum and vessel structure of the left internal thoracic and coronary arteries. J Thorac Cardiovasc Surg, 2005; 129: 767-772

58) Celletti FL, Waugh JM, Amabile PG, Brendolan A, Hilfiker PR, Dake MD: Vascular endothelial growth factor enhances atherosclerotic plaque progression. Nat Med, 2001; 7: 425-429

59) Ihling C, Szombathy T, Bohrmann B, Brockhaus M, Schaefer HE, Loeffler BM: Coexpression of endothelin-converting enzyme-1 and endothelin-1 in different stages of human atherosclerosis. Circulation, 2001; 104: 864-869

60) Pasterkamp G, Schoneveld AH, Hijnen DJ, de Kleijn DP, Teepen H, van der Wal AC, Borst C: Atherosclerotic arte- rial remodeling and the localization of macrophages and matrix metalloproteases 1,2 and 9 in the human coronary artery. Atherosclerosis, 2000; 150: 245-253

61) Sluimer JC, Gasc JM, van Wanroij JL, Kisters N, Groeneweg M, Sollewijn Gelpke MD, Cleutjens JP, van den Akker LH, Corvol P, Wouters BG, Daemen MJ, Bijnens AP: Hypoxia, hypoxia-inducible transcription factor, and macrophages in human atherosclerotic plaques are correlated with intraplaque angiogenesis. J Am Coll Cardiol, 2008; 51: 1258-1265

62) Sluimer JC, Daemen MJ: Novel concepts in atherogenesis: angiogenesis and hypoxia in atherosclerosis. J Pathol, 2009; 218: 7-29

63) Baba H, Yonemitsu Y, Nakano T, Onimaru M, Miyazaki M, Ikeda Y, Sumiyoshi S, Ueda Y, Hasegawa M, Yoshino I, Maehara Y, Sueishi K: Cytoplasmic expression and extracellular deposition of an antiangiogenic factor, pigment epithelium-derived factor, in human atherosclerotic plaques. Arterioscler Thromb Vasc Biol, 2005; 25: 19381944

64) Nakano T, Nakashima Y, Yonemitsu Y, Sumiyoshi S, Chen YX, Akishima Y, Ishii T, Iida M, Sueishi K: Angiogenesis and lymphangiogenesis and expression of lymphangiogenic factors in the atherosclerotic intima of human coronary arteries. Hum Pathol, 2005; 36: 330-340

65) Couffinhal T, Kearney M, Witzenbichler B, Chen D, Murohara T, Losordo DW, Symes J, Isner JM: Vascular endothelial growth factor/vascular permeability factor (VEGF/VPF) in normal and atherosclerotic human arteries. Am J Pathol, 1997; 150: 1673-1685

66) Luttun A, Tjwa M, Moons L, Wu Y, Angelillo-Scherrer A, Liao F, Nagy JA, Hooper A, Priller J, De Klerck B, Compernolle V, Daci E, Bohlen P, Dewerchin M, Herbert JM, Fava R, Matthys P, Carmeliet G, Collen D, Dvorak HF, Hicklin DJ, Carmeliet P: Revascularization of ischemic tissues by PlGF treatment, and inhibition of tumor angiogenesis, arthritis and atherosclerosis by anti-Flt1. Nat Med, 2002; 8: 831-840

67) Hughes SE, Crossman D, Hall PA: Expression of basic and acidic fibroblast growth factors and their receptor in normal and atherosclerotic human arteries. Cardiovasc Res, 1993; 27: 1214-1219

68) Kaartinen M, Penttila A, Kovanen PT: Accumulation of activated mast cells in the shoulder region of human coronary atheroma, the predilection site of atheromatous rupture. Circulation, 1994; 90: 1669-1678

69) Hansson GK, Libby P: The immune response in atherosclerosis: a double-edged sword. Nat Rev Immunol, 2006; 6: 508-519

70) Virmani R, Kolodgie FD, Burke AP, Finn AV, Gold HK, Tulenko TN, Wrenn SP, Narula J: Atherosclerotic plaque progression and vulnerability to rupture: angiogenesis as a source of intraplaque hemorrhage. Arterioscler Thromb Vasc Biol, 2005; 25: 2054-2061

71) Pepper MS: Role of the matrix metalloproteinase and plasminogen activator-plasmin systems in angiogenesis. Arterioscler Thromb Vasc Biol, 2001; 21: 1104-1117

72) Sueishi K, Yasunaga C, Castellanos E, Kumamoto M, Tanaka K: Sustained arterial injury and progression of atherosclerosis. Ann N Y Acad Sci, 1990; 598: 223-231 
73) Brodsky S, Chen J, Lee A, Akassoglou K, Norman J, Goligorsky MS: Plasmin-dependent and -independent effects of plasminogen activators and inhibitor-1 on ex vivo angiogenesis. Am J Physiol Heart Circ Physiol, 2001; 281: H1784-1792

74) Galis ZS, Sukhova GK, Lark MW, Libby P: Increased expression of matrix metalloproteinases and matrix degrading activity in vulnerable regions of human atherosclerotic plaques. J Clin Invest, 1994; 94: 2493-2503

75) Levy AP, Moreno PR: Intraplaque hemorrhage. Curr Mol Med, 2006; 6: 479-488

76) Hiraoka N, Allen E, Apel IJ, Gyetko MR, Weiss SJ: Matrix metalloproteinases regulate neovascularization by acting as pericellular fibrinolysins. Cell, 1998; 95: 365-377

77) Heinecke JW: Oxidized amino acids: culprits in human atherosclerosis and indicators of oxidative stress. Free Radic Biol Med, 2002; 32: 1090-1101

78) Sugiyama S, Okada Y, Sukhova GK, Virmani R, Heinecke JW, Libby P: Macrophage myeloperoxidase regulation by granulocyte macrophage colony-stimulating factor in human atherosclerosis and implications in acute coronary syndromes. Am J Pathol, 2001; 158: 879-891

79) Falk E, Shah PK, Fuster V: Coronary plaque disruption. Circulation, 1995; 92: 657-671

80) Falk E: Morphologic features of unstable atherothrombotic plaques underlying acute coronary syndromes. The American journal of cardiology, 1989; 63: 114E-120E

81) Gertz SD, Roberts WC: Hemodynamic shear force in rupture of coronary arterial atherosclerotic plaques. Am J Cardiol, 1990; 66: 1368-1372

82) Virmani R, Burke AP, Farb A, Kolodgie FD: Pathology of the vulnerable plaque. J Am Coll Cardiol, 2006; 47: C1318

83) Fernandez-Ortiz A, Badimon JJ, Falk E, Fuster V, Meyer B, Mailhac A, Weng D, Shah PK, Badimon L: Characterization of the relative thrombogenicity of atherosclerotic plaque components: implications for consequences of plaque rupture. J Am Coll Cardiol, 1994; 23: 1562-1569

84) Loree HM, Kamm RD, Stringfellow RG, Lee RT: Effects of fibrous cap thickness on peak circumferential stress in model atherosclerotic vessels. Circ Res, 1992; 71: 850858
85) Richardson PD, Davies MJ, Born GV: Influence of plaque configuration and stress distribution on fissuring of coronary atherosclerotic plaques. Lancet, 1989; 2: 941-944

86) Davies MJ, Richardson PD, Woolf N, Katz DR, Mann J: Risk of thrombosis in human atherosclerotic plaques: role of extracellular lipid, macrophage, and smooth muscle cell content. Br Heart J, 1993; 69: 377-381

87) Hansson GK, Libby P, Schonbeck U, Yan ZQ: Innate and adaptive immunity in the pathogenesis of atherosclerosis. Circ Res, 2002; 91: 281-291

88) Libby P: Molecular bases of the acute coronary syndromes. Circulation, 1995; 91: 2844-2850

89) Libby P: Coronary artery injury and the biology of atherosclerosis: inflammation, thrombosis, and stabilization. Am J Cardiol, 2000; 86: 3J-8J; discussion 8J-9J

90) Dollery CM, Owen CA, Sukhova GK, Krettek A, Shapiro SD, Libby P: Neutrophil elastase in human atherosclerotic plaques: production by macrophages. Circulation, 2003; 107: 2829-2836

91) Herman MP, Sukhova GK, Libby P, Gerdes N, Tang N, Horton DB, Kilbride M, Breitbart RE, Chun M, Schonbeck U: Expression of neutrophil collagenase (matrix metalloproteinase-8) in human atheroma: a novel collagenolytic pathway suggested by transcriptional profiling. Circulation, 2001; 104: 1899-1904

92) Sukhova GK, Schonbeck U, Rabkin E, Schoen FJ, Poole AR, Billinghurst RC, Libby P: Evidence for increased collagenolysis by interstitial collagenases- 1 and -3 in vulnerable human atheromatous plaques. Circulation, 1999; 99: 2503-2509

93) Libby P: Changing concepts of atherogenesis. J Intern Med, 2000; 247: 349-358

94) Sukhova GK, Shi GP, Simon DI, Chapman HA, Libby P: Expression of the elastolytic cathepsins $S$ and $\mathrm{K}$ in human atheroma and regulation of their production in smooth muscle cells. J Clin Invest, 1998; 102: 576-583

95) Galis ZS, Khatri JJ: Matrix metalloproteinases in vascular remodeling and atherogenesis: the good, the bad, and the ugly. Circ Res, 2002; 90: 251-262

96) Virmani R, Burke AP, Farb A, Gold HK, Finn AV, Kolodgie FD: Plaque Rupture. In: Renu Virmani JNMBLJTW, ed. The Vulnerable Atherosclerotic Plaque; 2007: 37-59 